\title{
Remote Laboratory for Measuring Linear Dimensions in the Process of E-Learning
}

\author{
http://dx.doi.org/10.3991/ijoe.v12i04.5102 \\ J. Šulc, D. Šešlija, S. Dudić and I. Milenković \\ University of Novi Sad, Novi Sad, Serbia
}

\begin{abstract}
Remote Laboratory for Measuring Linear Dimensions with remote access and control via Internet is developed and described in this paper. The system is realized at the University of Novi Sad, Faculty of Technical Sciences. This lab is dedicated to the students of secondary vocational schools and faculties with the aim to gain knowledge regarding linear dimension and mechanical component tolerance. Every user of this set-up is able to interact, observe and learn through the real measurement processes via communication infrastructure.
\end{abstract}

Index Terms-E-learning, Remote laboratories; Remote measurements.

\section{INTRODUCTION}

Traditional engineering education lessons at secondary vocational schools are based on theoretical explanations and exercises, which are solved by the students and checked by the teachers. This learning method has not evolved for many years, sometimes forcing students to believe in facts hardly demonstrable. Even if their results are correct, they are not able to check how the hypothetical system works in reality [1], if the school does not have appropriate equipment. Therefore, remote access to the practical experiment is very important for students.

One of the most promising possibilities for supporting student education is interaction with remote experiments by using internet connection. This way of learning and observation is more attractive and accurate for students. Learning and studying by using online resources has higher impact on student knowledge than traditional studying from books.

E-learning [2], [3], might be a connection between real experiments and theory from specific field of education. Students are able to perform real experiment, track experiment via video and collect the experiment results, by using electronic educational technology. With separate access to the learning material, scripts, multimedia presentations and other educational resources via Internet, teacher can check students knowledge at any stage in the form of continuous testing, also via Internet.

In this way, students gain more practical experience based on previously learned theory and they are ready to deal with the real problems.

This paper gives an overview of the experiment in the field of mechanical engineering, using mechatronic devices, its structure and real functioning over the Internet.

\section{GOALS}

Remote laboratory for measuring linear dimensions aims to offer a framework where tutors and trainees can communicate and interact remotely via Internet, in a blended or e-learning context to the different types of users, from secondary to higher education. It provides access to remote experiments in different areas of contemporary automated manufacturing technology and supporting materials.

Remote laboratory for measuring linear dimensions ensures reliable and accurate measurement of linear dimensions. This system is a good example of a mechatronic structure where different engineering areas, such as pneumatics, automation, mechanical engineering and programmable logic controllers (PLCs) are integrated in a unique one.

\section{DESCRIPTION OF REMOTE LAB For MEASURING LINEAR DIMENSION}

Remote laboratory for measuring linear dimension (Fig. 1) is developed to demonstrate different advanced technologies and to take care about important issues of overall system characteristics.

For the execution of the experimental set-up, four pneumatic cylinders of different sizes are used. Pneumatic cylinders provide the movement, and opening and closing of digital caliper. They allow the measuring device to comes in contact with the measurement object and perform measurement. Directional control valves for pneumatic cylinders are electrically controlled with the sensors output. Time-motion diagram is shown in Fig. 2.

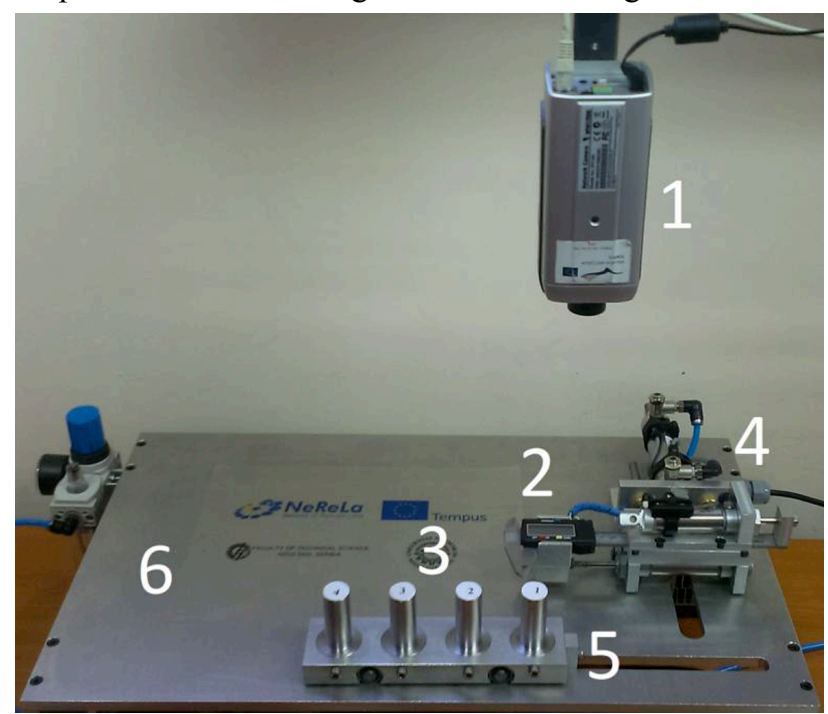

Figure 1. 1. IP web camera, 2. measurement device-digital caliper, 3. measurement object-axles, 4 . cylinders for movement of measurement device, 5. axles carrier, 6. platform. 


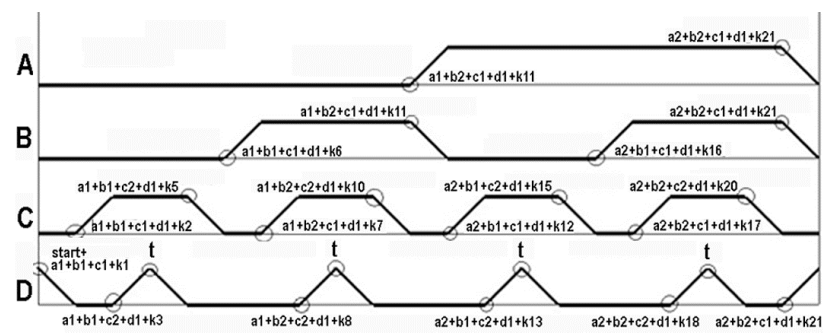

Figure 2. Time-motion diagram of execution part

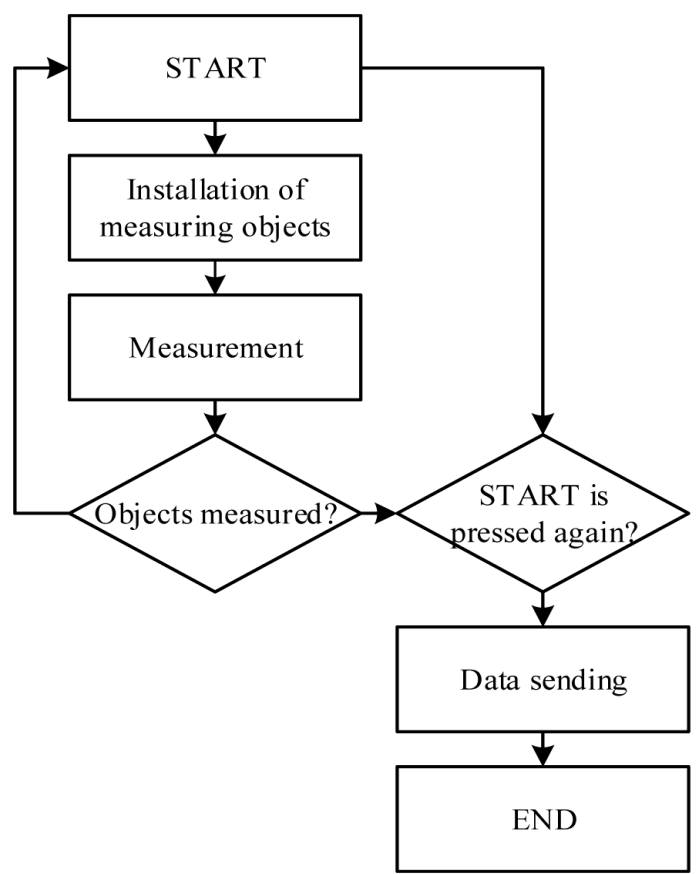

Figure 3. Working diagram

Data and clock signal from digital caliper are input signals that are driven and controlled by Arduino Yun. Web page is made by using JavaScript environment.

The measurement process starts to work by pressing the START button. After the measurement, results are sent to the microcontroller memory. If user, for some reason, wants to repeat this measurement, it can be done by reactivating the START button. If the data from previous measurement are not sent, the new data will not be saved. If the START button is pressed after storing data in microcontroller memory, new regular measurement cycle will begin. This working diagram is shown in Fig. 3.

The process structure of the e-learning via Internet, for a concrete demonstration example, consists of the following steps:

a) learning theoretical bases related to subject area,

b) experimental measurement with implementation of gained knowledge,

c) evaluation and validation of student knowledge and

d) results analysis.

All steps except the second are based on Moodle platform (Modular Object Oriented Dynamic Learning Environment). Teachers prepare all the necessary literature, regarding tolerances of mechanical parts and assemblies, and place it on Moodle, so students can access it any time. After reading theoretical basis students have all the necessary knowledge for starting the experiment. In order to access the experiment. Students need to open web browser

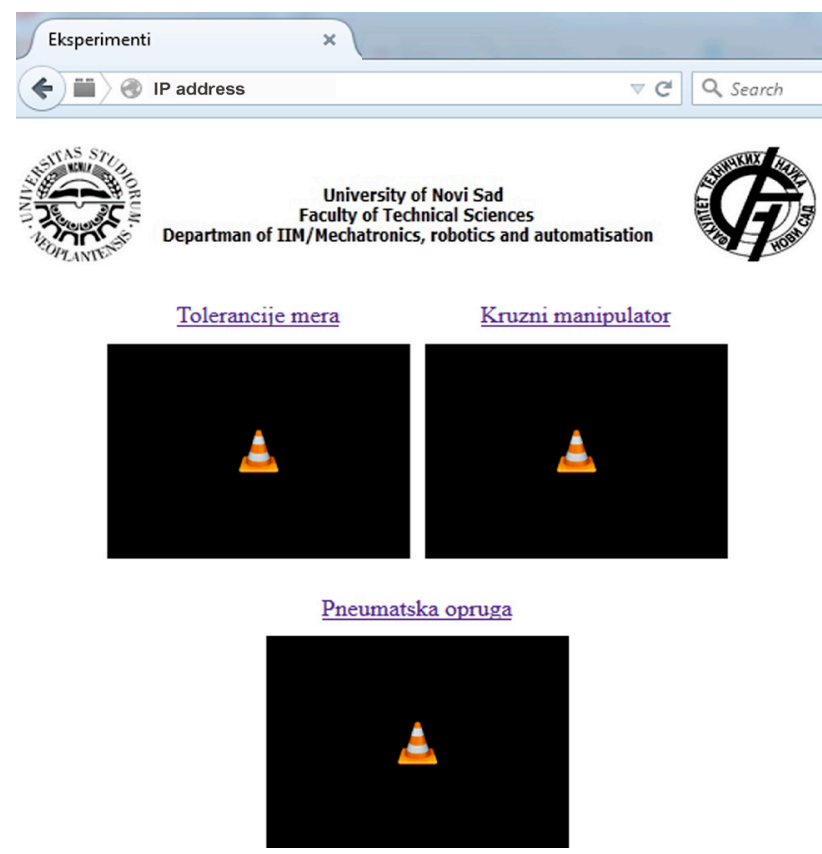

Figure 4. Start page for accessing to the remote experiments

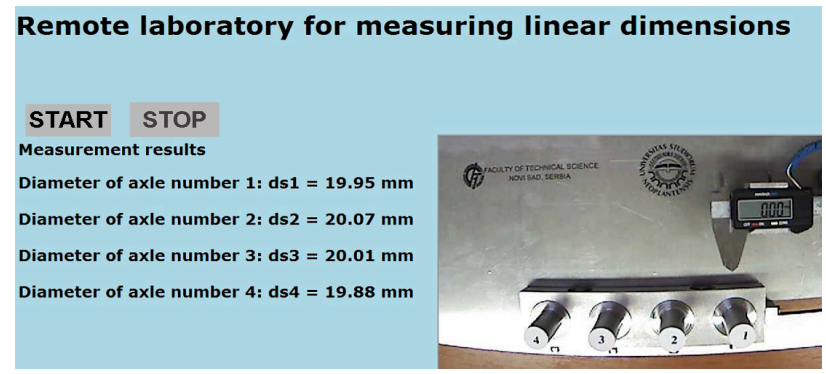

Figure 5. E-lab web client page, with camera and measuring results

\section{EXAM QUESTION}

\section{Test 1/Question 8}

Based on the experimental results of the axle dimension (Remote Lab included), determine which axle is made in tolerance j8.

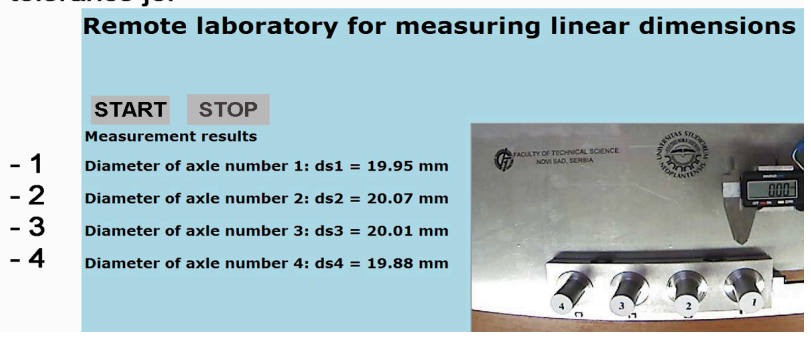

Figure 6. Example of one exam question

and enter the IP address. Than the start page shows (see Fig. 4).

By clicking the experiment, new tab is opening. Experiment than can be started by pressing START button. Upon completion of the measurement and by pressing the RESULTS button, students can see the measured diameter of installed axles (see Fig. 5).

At the end, students need to show their knowledge through the test their knowledge. It is possible to prepare several different types of tests, which can be located on Moodle. The example of one exam question is shown in Fig. 6. 


\section{CONCLUSION}

Multimedia components such as photos, animations and recordings, within this experimental set-up, give to the students as much realism as possible, related to the issues that might occur.

With the development of this experiment improvements in teaching methods should be promoted, as well as modernization of teaching processes and new perspective to the students. In addition, control activities can be practiced.

\section{REFERENCES}

[1] E. Cauhé et al., "RRLab: Remote Reality Laboratory to teach mechanics in schools," in IT Inovative Practices in Secondary Schools: Remote Experiments, Bilbao, Spain: Universidad de Deusto, 2013, ch. 6, sec. 2, pp. 119-140.

[2] L. Claesson et al., "Using a VISIR laboratory to supplement teaching and learning processes in physics courses in a Swedish upper secondary school," in IT Inovative Practices in Secondary Schools: Remote Experiments, Bilbao, Spain: Universidad de Deusto, 2013, ch. 7, sec. 2, pp. 140-175.

[3] F. Schauer et al., "INTe-L: wide open door for education by remote and virtual experiments exemplified on electricity, magnetism and electromagnetism," in IT Inovative Practices in Secondary Schools: Remote Experiments, Bilbao, Spain: Universidad de Deusto, 2013, ch. 9, sec. 2, pp. 205-251.

\section{AUTHORS}

J. Sulc is teaching fellow at the Faculty of technical Sciences, Department of industrial engineering and management, University of Novi Sad, Novi Sad, Serbia (email: sulc@uns.ac.rs).

D. Šešlija is full professor and Vice Dean for Science and International Cooperation at the Faculty of technical Sciences, Department of industrial engineering and management, University of Novi Sad, Novi Sad, Serbia (email: seslija@uns.ac.rs).

S. Dudić is assistant professor at the Faculty of technical Sciences, Department of industrial engineering and management, University of Novi Sad, Novi Sad, Serbia (e-mail: slobodan_dudic@yahoo.com).

I. Milenković is assistant professor at the Faculty of technical Sciences, Department of industrial engineering and management, University of Novi Sad, Novi Sad, Serbia (e-mail: ivanai@uns.ac.rs).

This paper is a result of activities within the NeReLa project "Building Network of Remote Labs for strengthening university-secondary vocational schools collaboration", No.543667-TEMPUS-1-2013-1-RSTEMPUS-JPHES, supported by The Education, Audiovisual and Culture Executive Agency (EACEA).

Submitted, 09 March 2015. Published as resubmitted by the authors on 09 April 2015. 